\title{
Ist die Spermienqualität jahreszeitabhängig?
}

Ist die Spermienkonzentration im Winter am höchsten oder im Frühjahr? Gibt es überhaupt nennenswerte Unterschiede in den verschiedenen Jahreszeiten? Chinesische Forscher haben den Zusammenhang anhand von mehr als 13.000 Spermienproben untersucht.

tudien zu jahreszeitlichen Schwankungen der Spermienqualität hatten in der Vergangenheit oft zu sehr widersprüchlichen Ergebnissen geführt. Weitere aktuelle Daten gibt es nun aus der chinesischen Provinz Zhejiang. Dort ist das Klima von feuchtheißen Sommern und kurzen kühlen Wintern geprägt. Im Juli liegt die Durchschnittstemperatur bei 27-30 ${ }^{\circ} \mathrm{C}$ und damit mehr als $10{ }^{\circ} \mathrm{C}$ über der von Berlin, im Januar bei etwa $2-8^{\circ} \mathrm{C}$.

Analysiert wurden mehr als 13.600 Proben von Samenspendern einer Samenbank. Die Urologen schauten zunächst, wann die Proben entstanden: im Winter (17. Dezember bis 11. Februar), Frühjahr (12. Februar bis 14. April),
Frühsommer (15. April bis 28. Juni), Hochsommer (29. Juni bis 3. September), Spätsommer (4. September bis 5. November) oder Herbst (6. November bis 16. Dezember). Anschließen verglichen sie die Spermienqualität mit der durchschnittlichen Tageshöchsttemperatur in diesen sechs Jahreszeiten.

Sowohl das Volumen des Ejakulats als auch Konzentration und Motilität der Spermien machten im Hochsommer einen deutlichen Knick - die Hitze scheint der Spermatogenese nicht zu bekommen. Am höchsten war das Probenvolumen im Frühjahr mit $3 \mathrm{ml}$, am niedrigsten im Hochsommer mit 2,3 ml. Die Spermienkonzentration variierte zwischen 80
Millionen/ml im Hochsommer und 90 Millionen/ml zwischen Herbst und Frühjahr: Der Anteil motiler Spermien schwankte zwar signifikant, aber gering zwischen $62,5 \%$ im Frühjahr und $61 \%$ im Hochsommer. Bei größter Hitze war auch der Anteil von defekten Spermatozoen am höchsten (83\%), am niedrigsten war dieser Anteil im Winter (81,4\%).

Fazit: Bei fast allen Qualitätsparametern ließ sich ein signifikanter Unterschied zwischen Hochsommer und den übrigen Jahreszeiten ausmachen. Dagegen waren die Unterschiede zwischen den anderen Jahreszeiten gering bis nicht signifikant. Eine deutliche Beeinträchtigung der Spermienqualität scheint folglich nur bei starker Hitze gegeben. Dies mag erklären, weshalb bisherige Studien $\mathrm{zu}$ recht inkonsistenten Ergebnissen führten.

Thomas Müller

Zhang XZ et al. Seasonal variation in semen quality in China. Andrology 2013; 1: 639-43

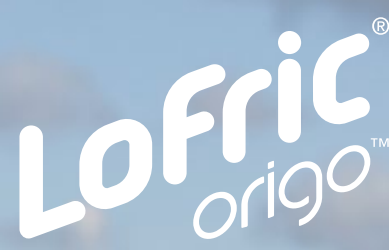

Sichere Katheterisierung in einer cleveren Verpackung.

Bestellen Sie noch heute Muster und Informationsmaterial unter unserer kostenlosen Service-Hotline 0800 / 2727872. 